This item was submitted to Loughborough's Research Repository by the author.

Items in Figshare are protected by copyright, with all rights reserved, unless otherwise indicated.

\title{
Mathematics lecturing in the digital age
}

PLEASE CITE THE PUBLISHED VERSION

http://dx.doi.org/10.1080/0020739X.2011.646325

\section{PUBLISHER}

(c) Taylor and Francis

\section{VERSION}

AM (Accepted Manuscript)

\section{PUBLISHER STATEMENT}

This work is made available according to the conditions of the Creative Commons Attribution-NonCommercialNoDerivatives 4.0 International (CC BY-NC-ND 4.0) licence. Full details of this licence are available at: https://creativecommons.org/licenses/by-nc-nd/4.0/

\section{LICENCE}

CC BY-NC-ND 4.0

\section{REPOSITORY RECORD}

Trenholm, Sven, Lara Alcock, and Carol L. Robinson. 2019. "Mathematics Lecturing in the Digital Age". figshare. https://hdl.handle.net/2134/26098. 


\section{Mathematics Lecturing in the Digital Age}

Sven Trenholm; Lara Alcock; Carol L. Robinson

Mathematics Education Centre, Loughborough University, Loughborough, UK

Sven Trenholm

Mathematics Education Centre

Loughborough University

Loughborough, Leicestershire

LE11 3TU, UK

S.Trenholm@lboro.ac.uk

+44(0) 1509228212 


\title{
Mathematics Lecturing in the Digital Age
}

\author{
Sven Trenholm; Lara Alcock; Carol L. Robinson
}

In this paper we consider the transformation of tertiary mathematics lecture practice. We undertake a focused examination of the related research with two goals in mind. First, we document this research, reviewing the findings of key studies and noting that reflective pieces on individual practice as well as surveys are more prevalent than empirical studies. Second, we investigate issues related to the transformation of lecture practice by the emergence of electures. We discuss the latter in terms of claims about the efficiencies offered by new technologies and contrast these with possible disadvantages in terms of student engagement in a learning community. Overall findings indicate that while survey results appear to trumpet the value of e-lecture provision, empirical study results appear to call that value into question. Two explanatory theoretical frameworks are presented. Issues concerning the instructional context (e.g. the nature of mathematical thinking), inherent complexities and recommendations for implementation are discussed.

Keywords: lecture; e-learning; mathematics; instructional technology; online learning

\section{Introduction}

Higher education practice is in the midst of what has been termed an "almost unprecedented" transformation (Redden, 2009). Whereas the live lecture has been the dominant instructional strategy employed in higher education at least since the Middle Ages (Crosby, 1936), the present digital age presents perhaps the first serious challenge to its dominance.

For our purposes, a lecture will be defined "as one person speaking, more or less continuously, to a group of people on a particular subject or theme" (Fardon, 2003, p.701). The traditional lecture refers to a lecture that takes place in a classroom or lecture theatre and is both live and "face-toface". An e-lecture will be defined in accordance with Jadin, Gruber \& Batinic (2009) as "a media based lecture including (such things as) an audio or video recording, synchronized slides, table of contents and optional complementary information (e.g., external links)" (p.282). To clarify, we define e-lectures as those lectures that are not face-to-face but rather mediated using some 
combination of hardware and software. Also, by 'recording', we restrict ourselves to those lectures that are provided after the actual live lecture ${ }^{1}$. Other terms used are web-based, digital or online lecture, webcast, screencast, podcast or lecture cast. E-lecture presentations can vary widely and may be characterized in at least three ways: production (live or staged), presentation (combination of one or more of audio/video/screen) and presentation use (supplementing or replacing the live lecture). Video presentations vary from headshots to wide-angle views. Screen presentations might use text and/or handwriting that is presented either dynamically (e.g. solution is demonstrated accompanied by an audio explanation) or statically (e.g. complete solution is shown accompanied by an audio explanation). Uses of e-lectures vary from optional supplement to large-scale replacement of traditional lectures (e.g. Greenberg \& Williams, 2008). In some cases, they may be designed to be used before lecture contact time in order to move the content delivery outside of the lecture room so that more time is spent on interactive instruction (e.g. student problem solving). For example, Berque, Byers and Myers (2008) speak of "turning the classroom upside down" when using the e-lecture in the pre-lecture modality for computer science students. In our search, we did not find any evidence of this modality with respect to tertiary mathematics learning and hence the focus in this article is on e-lectures used as a post-lecture supplement or full replacement for live lectures. As we will argue later, the variety possible in e-lecture presentation gives flexibility to lecturers but can make it difficult to compare across research studies in this area.

In mathematics, as in other areas, e-lectures of various kinds are becoming more common and, while there has been a growing body of research on lecturing and e-lecturing in general, many authors are calling for more attention to disciplinary context (e.g. Cretchley, 2005). The goal of this paper is to focus specifically on research relating to tertiary mathematics lecturing: to document the current research and to discuss issues raised by the emergence of e-lectures.

\footnotetext{
${ }^{1}$ That is, our focus is on asynchronous provision. Those forms of lectures provided synchronously, such as video-conferencing, are excluded.
} 


\section{Research on mathematics lecturing and e-lecturing}

For this paper we sought English-language $\operatorname{articles}^{2}$ that focused directly on tertiary mathematics lecturing practice. Searches, detailed below, were first undertaken in the fields of mathematics education, instructional technology and computer-mediated learning; these were followed by a general online search. Articles were restricted to those with variations of the word "lecture" (e.g. lecturing, lectures and lecturer) in the title and the search was undertaken using the Google Scholar search engine (see Harzing \& Van der Wai, 2008).

In the field of mathematics education, we searched journals on the University of Southampton mathematics education research journal listing (http://www.crme.soton.ac.uk/links/journals.html). Two additional sources (MAA’s College Math Journal, Mathematics Magazine and Journal of Online Mathematics and its Applications) were also included, as were the proceedings of eight mathematics education conferences ${ }^{3}$ : (International Group for the Psychology of Mathematics Education (PME; 2005-2009), British Society for Research into Learning Mathematics (BSLRM;

2000-2009), Conference of European Research in Mathematics Education (CERME; 2000-2009), International Conference on Technology in Mathematics Teaching (ICTMT; 2007 and 2009), Mathematical Association of America Research in Undergraduate Mathematics Education (SIGMAA-RUME; 2002,2005-2010), American Mathematical Association of Two-Year Colleges (AMATYC; 2000-2009), International Conference on Technology in Collegiate Mathematics

(ICTCM; 2000-2010) and the Mathematics Education Research Group of Australasia (MERGA; 2002, 2004-2010).

In instructional technology and computer-mediated learning our search used articles that provided a ranking of journals of importance. In the field of instructional design, using a citation analysis for

\footnotetext{
${ }^{2}$ A small number of the conference proceedings articles were in the form of PowerPoint presentations.

${ }^{3}$ Reasonable attempts were made to capture all relevant conference articles between 2000 and 2009. In many cases proceedings could not readily be accessed (e.g. broken website link) and therefore these years were excluded.
} 
all 1980-2008 journals (Ozcinar, 2009), all thirteen top listed journals were searched. In the field of computer-mediated learning, based on a ranking of popularity, importance and prestige (Elbeck \& Mandernach, 2009), the top 15 journals were searched. Using Google Scholar, searches were undertaken with the journal designated and variations of 'lecture' in the title specified. Following this, articles were examined and only those with a disciplinary focus on mathematics were included.

A final general web search was performed for any scholarly articles focused on mathematics lecture practice. This was accomplished using the basic Google web search engine with combinations of variations of the word "lecture", various known terms associated with e-lecturing (e.g. "online lecture", "web-based lecture", "webcast", "screencast", "lecture cast" or "digital lecture”) and "mathematics". This allowed us to identify articles such as book chapters or other relevant publications that were heavily referenced.

As with all literature searches, publication bias presents a possible limitation (Torgerson, 2006). This may be of particular interest given the current educational environment where lecturing is being challenged as an 'outmoded' way of teaching (Jones, 2007, p.399) and, where some suggest that there is a prevailing 'techno-positivism' that tends to view instructional technology in a positive light (Njenga \& Fourie, 2010). Thus it is possible that searches may be skewed toward positive interpretations.

The resulting articles were classified by source (journal, proceedings and an 'other' category capturing such things as official newsletter articles and book chapters) and then by type of work (reflective, empirical; see Table 1). The empirical studies were then further classified by type of data used (see Table 2). Table 2 will be discussed at length in the next section.

Two line graphs were also constructed showing cumulative article count by date. Figure 1 shows all articles by the three types. Figure 2 shows all journal articles with newer journals excluded (i.e. excluding articles from journals with a post-1993 inception date). While all figures indicate a 
growing interest in mathematics lecture practice as an area of study and research, the second figure indicates that the balance of interest appears to be shifting towards empirical studies. Naturally, this growth in interest in lecture practice may be directly related to the extent of web use and broadband penetration in the general population (e.g. Horrigan, 2009).

In the following subsections, we first review the main findings from the empirical studies then draw out major themes from reflective articles and self-report surveys.

\subsection{Empirical research studies}

Of the 23 empirical studies reported (see Table 2), 11 used one or more of the following types of data: $\log$ files (five studies - four used server log records and one relied solely on student selfreporting), academic records (seven studies - all either actual or self-reported e.g. grades and/or attendance), psychometric instruments (three studies - e.g. measuring student approaches to studying). Many of these studies additionally used student self-report data. These 11 studies are discussed in this subsection. The remaining 12 studies used only self-report survey data with little statistical analysis. They are discussed along with the reflective articles in the following subsection.

Five of the 11 empirical studies used $\log$ file analysis to investigate actual student behaviour. First, Joordens, Le, Grinnell, Chrysostomou's (2009) study, involving a total of 488 Canadian students from two calculus classes, analysed log files recording student use of optional e-lecture provision to investigate the relationship between feature usage (pause, seek) and academic performance. They found that "students who both attended and watched lectures online, and those who pause online lectures frequently, actually performed worse in the course" (p.286). Second, Inglis, Palipana, Trenholm and Ward (in press) also studied log files for three UK calculus classes involving a total of 534 students. In this case, log files were used in conjunction with regular lecture attendance and use of a mathematical learning support centre. Inglis et al. identified four clusters of student attendance behaviours; they found that the cluster who made heavy use of live lectures performed 
best in terms of course grades and that those who, instead, made heavy use of the e-lectures performed significantly worse. Third (from a weaker basis due to reliance on self-report data), Cascaval, Fogler, Abrams and Durham (2008) studied student self-reported grade and e-lecture use data from seven different mathematics courses at one US University. A 40-item survey and demographic questions were sent to all 147 students with 51 responding. Cascaval et al. highlighted the perceived added value of e-lectures (both in terms of performance and student experience), but the only correlation provided (for only two of the seven courses), between e-lecture use and grade earned, was slightly negative. The remaining two studies found in conference proceedings are not discussed due to lack of clear methodology. Clearly the first three studies indicate that higher e-lecture use is at least weakly associated with poorer performance, with the first suggesting causality on the basis of flexible viewing options.

Of the six remaining studies, we now discuss the three that used psychometric instruments. First, Le, Joordens, Chrysostomou, \& Grinnell's (2010) study, with 64 Canadian calculus students, follows up on Joordens et al.'s (2009) study, by performing a second experiment using the revised two-factor Study Process Questionnaire (R-SPQ-2F; Biggs, Kember, Leung, 2001) to measure students' learning approaches and investigate how these correlate with viewing strategies. They found that students with surface learning strategies tended to be those who used the pause feature more often and argued that this feature of e-lectures was enabling them to memorize and not understand the material. Second, Macedo-Rouet, Ney, Charles and Lallich-Boidin (2009) compared web-based to paper-based lecture notes with 122 French students answering differential equations and statistics questions. Using an adapted version of the NASA-TLX scale (Hart \& Staveland, 1988), composed of six dimensions of cognitive load (mental, physical, temporal, effort, performance and frustration), they found that those who used paper lecture notes were the highest performing students and that web delivery "imposed higher perceived cognitive load" (p.375). Third, Cretchley's (2005) study of 85 Australian students in an Algebra and Calculus course used 
questionnaire, grade and attendance records along with a measure of student approaches to studying to help determine what motivates students to attend lectures. To measure approaches to studying, the Approaches and Study Skills Inventory for Students (ASSIST; Tait, Entwistle \& McCune, 1998) was used. This instrument provides a measure of student engagement on three scales: surface, deep and strategic. Cretchley found that the more students attended live lectures the better they performed, with no significant difference in performance related to highly strategic study approaches. The first two studies echo findings from log file analyses; the latter continues to raise concerns regarding computer-mediated lecture practice.

Three studies used two forms of academic records. Two are discussed here while the third study, from conference proceedings, is excluded due to a small sample size. Waits (1970), the earliest study found, compared the academic achievement of 971 US students in a mathematics for nonscience majors course divided into three groups: a live traditional lecture format and two forms of recorded presentations by television. He found that those in the traditional lecture group had statistically significantly higher academic achievement, although he stated that this might be related to the live lecturer's "celebrity" appeal. Finally, Jaki (2009), representative of the wide interest and general findings regarding the impact of e-lectures on traditional lecture attendance, examined records of 130 UK students in an introductory statistics course and found no real impact.

Overall, findings appear to indicate cause for concern regarding the implementation and use of electures in mathematics. Undoubtedly further research is required to better understand the dynamics that the present research has only begun to reveal. In the interim, as the following section indicates, student views of e-lecture provision appear to contrast with empirical research findings.

\subsection{Reflective articles and self-report survey findings}

This section provides a summary of reflective and self-report study findings as reported from the perspective of the institution, lecturer, and student. Institution and lecturer perspectives are derived 
primarily from reflective articles, while student perspectives are primarily from self-report surveys.

From an institutional perspective, e-lectures and other e-learning facilities can provide great efficiencies in terms of staff time. They are often seen as a necessary development in satisfying student demand and increasing/maintaining institutional marketability, and as providing a high return at a relatively low cost (Cascaval et al., 2008).

From a lecturer's perspective too, efficiency is gained, particularly in automation of routine administration, provision of problem solutions, ability to pre-record material to cover for absences, and ability to track student progress (Mullamphy, Belward, Ward \& Ward, 2010). However, this has been seen as coming with costs in terms of upfront investment of time and money (e.g. Chow, 2008), technology issues such as reliability (Macedo-Rouet et al., 2009), as well as a perceived threat to job security (Mullamphy et al., 2010). With regard to the actual experience of lecturing, traditional lectures are sometimes favored over e-lectures because, for example, they allow a lecturer to effectively communicate their enthusiasm and thus motivate students (Cretchley, 2005).

Similar results are found from a student perspective. Survey findings report a favorable view of electure provision, with students citing such reasons as increased flexibility and convenience (e.g. Le et al., 2010). Students too, however, widely report that they still value live lectures, citing reasons such as a sense of community (Cretchley, 2005) and immediacy in feedback (Mullamphy et al., 2010). These issues of efficiency and flexibility versus community and immediacy in feedback are discussed in the next main section, after some comments on methodological issues regarding the research we have reviewed.

\subsection{Comments on research methods}

If one wishes to make decisions about the value of e-lecturing in mathematics, the most obvious problem with current research is the preponderance of reflective pieces and, in particular, self-report 
studies about students' learning experience. Such studies are in keeping with an institutional emphasis on student satisfaction, but the results may bear little relationship to academic achievement. As summarized above, students generally like having access to e-lectures, but existing research suggests that use of such resources is negatively correlated with academic performance (Cretchley, 2005; Cascaval et al., 2008; Le et al., 2010; Inglis et al., in press). Indeed, there is still no controlled experiment in mathematics to test the efficacy of e-lectures. Across all disciplines, Figlio, Rush and Lin (2010) claim their experiment in an introductory microeconomics course to be the only such experiment to date. They write: "the current state of this research is dismaying: more students are being exposed to internet classes yet there is no satisfactory research demonstrating whether such changes help, hinder, or have no effect on student learning" (p.5). More research is needed to help clarify the nature of this relationship so that the profusion of selfreport studies does not lead to the creation of a mirage of benefit.

A subtler issue in interpreting the findings of this research is related to the variety of possible electure presentation types and the issue of whether access to e-lectures is an optional add-on to an existing course, or is intended as a full replacement. If the exact nature of the e-lecture is not fully described (which is not uncommon in the articles found in this search) it is difficult to compare or generalize study results.

\section{Discussion: efficiency, flexibility and community}

The results about the perceived value of e-lectures might not stand up in the face of more rigorous investigation of their contribution to student learning. However, it seems likely that their use will increase because institutions will continue to seek ways to capitalize on both the apparent efficiency and appeal to student satisfaction that they offer. We believe it is thus of value to clarify the relationships between the various claims made on behalf of e-lectures. We do so in this section, relating our discussion to wider theoretical issues of concern to the mathematics education research 
community.

\subsection{Efficiency Gains}

Large-scale efficiency, in the sense of instructing the maximum number of students for the minimum cost, is primarily an institutional concern. E-lecturing may seem to present a plausible means of achieving greater efficiency particularly given the potential for scalability in traditional mathematics lecture classes (Cheng, in press; Warren, 1988). With the aim of using lecturers' time efficiently by allowing them to communicate material to a large number of students at once, the contribution of e-lectures may be seen as an extension of that made by traditional lectures, with the exception that the potential for scaling up is enormously amplified (e.g. Greenberg \& Williams, 2008). The critical differences, however, are the changes in medium and mode of delivery. With these come other changes, two of which we will focus on here: increased flexibility of access and decreased human interaction.

\subsection{Flexibility Gains}

Increased flexibility is noted and valued by students to whom e-lectures are available (e.g. Preston, Phillips, Gosper, McNeill, Woo, \& Green, 2010). Valuing such flexibility is also in keeping with suggestions among educators that instruction would be better if it were more individualised. Compared with a traditional lecture, an e-lecture allows each individual student more control, including the ability to search for, pause and replay material perceived as difficult. Of course, the research above suggests that students might not always use these facilities effectively. One thing does appear clear, as Le et al. (2010) report in their study in mathematics; students require instruction in how to use e-lectures effectively. However, we do not yet know what this instruction should look like.

Beyond simple recorded lectures, one might also consider more flexible systems of interaction with 
materials and tutors; although such systems might still involve a lack of immediacy in feedback (Mullamphy et al., 2010), they have the potential of going well beyond the levels of interaction typical of traditional lectures. Thus e-lectures and associated technological developments (e.g. threaded discussions or online assessment) could partly address concerns that traditional lecture practice does not respond effectively to the needs of individual students.

\subsection{Interaction and Community}

However, e-lectures may lead to a decrease in human interaction. If students can access e-lectures as an alternative to attending live lectures, some of them will choose to do so (Inglis et. al., in press). Computer-mediated automation of lecture delivery can thus represent a change whereby the "transaction between the impersonal (world of ideas) and the personal (world of the student)" is no longer conducted through the live interpersonal relation of teacher with learner (Pring, 2001, p.106). This might not be a major concern if one views lecturing as primarily the one-way transmissive delivery of material, but it seems considerably more serious if one instead believes that the primary purpose of the mathematics lecture is to seed student learning (whether it is delivered live or online), demonstrating the values and practices of the subject (Pritchard, 2010). This purpose is consistent with recent arguments for the importance of social psychological dynamics and subtler forms of two-way communication, such as body language and cues (e.g. Hofacker \& Ernie, 2009), communicating tacit knowledge (Ernest, 1999; Goodyear, 2002) or, particularly if the lecture production is staged, phatic forms of communication (Casalegno \& McWilliam, 2004). In mathematics, Rood (2003) goes one step further, arguing that "some 'spiritual' experience can occur in a good mathematics lecture and this experience is motivating for students and contributes to their enculturation within a mathematics community" (p.16). Indeed, such a community might be a key factor in effective learning: Overbaugh and Nickel (2011), summarizing numerous prior studies, conclude that there is a "positive relationship between heightened sense of community and higher-level thinking and problem solving" (p.4). Attempts have been made to replicate 
mathematical learning communities online (e.g. Pomper, 2007), but these may not replace all aspects of live interaction. And though web-based communication presents the possibility of increasing dialogue, current problems related to effective two-way mathematical communication (i.e. use of math notation and diagrams) may limit the extent to which the dialogue can occur (Lingefjärd \& Holmquist, 2002; Smith, Torres-Ayala, \& Heindel, 2008).

\subsection{Explanatory frameworks}

Whatever the case regarding its benefits, given the generally positive reviews, it is possible that at least some students benefit (in terms of achievement) from e-lectures. With this in mind, two theories, those of communities of practice (Wenger, 2000) and transactional distance (Moore, 1993) are considered as relevant explanatory frameworks. First, Moore (1993), in his theory of transactional distance, posits that the impact of separating students from instructors is mediated by three pedagogical variables that he terms dialogue, structure and learner autonomy. Dialogue is viewed as the process of interaction when instruction is given and the student responds (e.g. email feedback). Structure refers to the course design and, in particular, the rigidity or flexibility of the pedagogical approach (e.g. instructional strategies or assessment). Finally, learner autonomy is the degree to which the student controls the learning process (e.g. goal setting or resources used). Within this framework, e-lectures generally present a learning environment that is highly structured with little or no dialogue. This, Moore would argue, presents a situation with high transactional distance that requires students to exercise greater learner autonomy in order to be successful. Within this framework, it can be argued that students with such characteristics might use e-lectures more successfully than others.

In view of situated learning (Lave \& Wenger, 1991) in a community of practice (Wenger, 2000), electures seem to present a difficult challenge. When students use e-lectures to replace live lectures they effectively remove themselves, at least temporarily, from their community of practice. 
Situated learning (Lave \& Wenger, 1991) argues that without adequate participation (i.e.

interaction), a student is essentially situated at the periphery of the community and thereby

effectively becomes stunted in their development from novice to expert. In Wenger's (2000)

community of practice view, the ability to engage and align their activities with other members is

potentially lost. Therefore, as seen through the framework of situated learning within a community

of practice, it seems reasonable to expect that these students may experience depressed learning of

some form.

In short, while both Wenger's (2000) and Moore's (1993) frameworks may present plausible explanations for findings on mathematics e-lecture use, further research is required to fully understand the impact of e-lectures on student learning in general, and in mathematics learning in particular.

\subsection{The nature of mathematical thinking}

While the negative correlation of use to achievement appears to support Wenger's (2000) framework, the nature of mathematics e-lecturing and its impact on achievement still remains unclear. Some, for example, from experience, have conjectured that e-lectures in mathematics help the best students get better and the lowest performing students get worse (Feinstein, 2010; oral communication). Outside of mathematics, based on study findings in health sciences, others have suggested the opposite: that lower achieving students benefit more than higher achieving (Owston, Lupshenyuk, \& Wideman, 2011). This contrast may help highlight the significance of considering the disciplinary context (e.g. epistemology and ontology) when considering e-lecture development. Whereas in Owston et al.'s (2011) study iterative e-lecture viewing is seen as a benefit in helping the material "sink in" (p.20), in Le et al.'s (2010) study, this "sinking in" is equated with rote memorization in a discipline where conceptual understanding is emphasized (i.e. a disciplinary context with an epistemological structure that emphasizes conceptual linkages and an ontological 
structure that emphasizes logically-reasoned argumentation). In a similar context (distance learning) others have noted the combined challenge of the conceptual nature of mathematics with the "quasi-separation" of the student from the lecturer (Tsvigu, Breiteig, Persens, \& Ndalichako, 2008). This challenge may be re-phrased as: while a one-way information transfer may suffice, for example, in a fact-based discipline (e.g. health science), the learning of mathematics is better served by a two-way exchange that facilitates, for example, the flexibility required for advanced mathematical thinking (Tall \& Dubinsky, 1996). In short, e-lecture research in general, should not be considered in a de-disciplined or generic fashion but must be interpreted with respect to its context (e.g. discipline).

\subsection{Further complexities}

Current research, and the related development, necessarily must consider other differentiated factors that also present further complexities. First, for example, if the lecturer represents something less than a "leader of minds" (Rood, 2003), then the e-lecturing experience might be as good as or better than the traditional experience. Second, so-called distraction technologies are increasingly ubiquitous: a student studying an e-lecture at home might be diverted by other internet content (cf. Carr, 2010), but so might a student who can access content on a mobile phone during a lecture. Such distractions may undermine the status of a lecture as, what Young (2010) terms, "sacred space”. Relatedly, the consensus that is emerging indicates that within-lecture multi-tasking depresses learning (Hembrooke and Gay, 2003).

Clearly the problems of lecturing in the digital age are complex. Institutions, lecturers and students all value the efficiency and flexibility offered by technologically-mediated e-lectures, and traditional lectures might also be rendered less effective by technologically-enabled distractions. As research begins to unravel this complexity, current findings appear to suggest that student use of e-lectures in mathematics may encourage and enable a form of learning that is in conflict with the 
disciplinary nature of mathematics (i.e. encourage rote learning versus conceptual understanding).

Certainly, while such learning occurs in live lectures as well, the difference may be that e-lectures allow students to remove themselves from an obvious community of practice and thus miss out on valuable human interaction that may help correct such approaches to learning. It may also be possible that any such detriment, caused by the separation of the student from this learning community, may be mediated by student characteristics such as learner autonomy.

\section{Conclusion}

Influenced by wider cultural factors, lecture practice in higher education is undergoing a transformation, one significant aspect of which is the increased provision of e-lectures. In tertiary mathematics, the educational costs and benefits of these changes are currently unclear. While student and lecturer satisfaction is clearly noted, the little empirical evidence that exists indicates a negative correlation between e-lecture use and achievement, which raises questions about the impact of e-lectures on community and its related impact on learning outcomes.

Until research findings are clearer, as traditional institutions consider providing e-lectures, it seems prudent to avoid what Baker, Hale and Gifford (1997) refer to as a "bolt-on" instructional technology strategy that ignores the bigger picture of pedagogic transformation. That is, there is a need for careful planning (Overbaugh \& Nickel, 2011) which, in its most basic form, entails providing instruction to students on how best to make use of e-lectures (Le et al., 2010). In a more demanding form, this planning may entail serious consideration of student demographic characteristics and how to mitigate the possible effects of any loss of community.

As mentioned throughout this paper, many questions remain. In particular, what might be the reasons for the negative correlation between e-lecture usage and achievement? Is it that weaker students tend to take advantage of these resources more than stronger students who may not require 
additional help or is it the case that too much flexibility (i.e. pause, rewind, play viewing features) enables students to pursue surface learning strategies? While technology may drive, and be driven by, mathematics pedagogy to the benefit of student learning (e.g. Moore, 1997), we would argue that the nature of mathematical thinking needs to drive the adoption and use of technology, and not

the reverse. In the realm of e-lecture practice, how this could be realized remains to be understood. In the interim, technological changes continue to produce more questions and, with regards to mathematics lecture practice in general, it is unclear whether or when new well-evidenced norms for practice will emerge.

\section{References}

Baker, W., Hale, T., \& Gifford, B. R. (1997). From theory to implementation: The mediated learning approach to computer-mediated instruction, learning and assessment. Educom Review, 32(5), 42-50.

Berque, D., Byers, C. And Myers, A. (2008). Turning the Classroom Upside Down Using Tablet PCs and Dyknow Ink and Audio Tools. In R. Reed, D. Berque and J. Prey (Eds.) The impact of Tablet PCs and pen-based technology on education: evidence and outcomes. 3-9, Indiana, US, Purdue University Press

Biggs, J., Kember, D., \& Leung, D. Y. P. (2001). The revised two-factor study process questionnaire: R-SPQ-2F. British Journal of Educational Psychology, 71(1), 133-149.

Carr, N. (2010). The shallows: How the internet is changing the way we think, read and remember. London, UK: Atlantic.

Casalegno, F., \& Mc William, I. M. A. (2004). Communication dynamics in technological mediated learning environments. International Journal of Instructional Technology and Distance Learning, 1(11), 15-33.

Cascaval, R., Fogler, K., Abrams, G., Durham, R. (2008). Evaluating the benefits of providing archived online lectures to in-class students enrolled in Math courses, in Journal of Asynchronous Learning Networks, 12(3-4), 61-70.

Cheng, D. (In Press). Effects of class size on alternative educational outcomes across disciplines. Economics of Education Review. doi:10.1016/j.econedurev.2011.04.009 
Chow, O. P. (2008). Math podcasting to go - design, purpose, format, delivery. Proceedings of American Mathematical Association of Two Year Colleges Conference. Accessed August 4, 2011: http://www.amatyc.org/publications/Electronicproceedings/2008DC/proceedings.html

Cretchley, P. (2005). Mathematics and dumping lectures?: Another perspective on the shift towards learner pragmatism. Proceedings of the Fifth Southern Hemisphere Conference on Undergraduate Mathematics and Statistics Teaching and Learning, 42-48. Accessed August 4, 2011: http://eprints.usq.edu.au/764/1/Cretchley_2005_Delta05.pdf

Crosby, R. (1936). Oral delivery in the middle ages. Speculum: A Journal of Mediaeval Studies, 11(1), 88-110.

Elbeck, M., \& Mandernach, B. J. (2009). Journals for computer-mediated learning: Publications of value for the online educator. The International Review of Research in Open and Distance Learning, 10(3). ISSN: 1492-3831. Accessed August 4, 2011: http://www.irrodl.org/index.php/irrodl/article/view/676/1268

Ernest, P. (1999). Forms of knowledge in mathematics and mathematics education: Philosophical and rhetorical perspectives. Educational Studies in Mathematics, 38(1), 67-83.

Fardon, M. (2003). Internet streaming of lectures; a matter of style. Proceedings of Educause 2003. Adelaide, University of Adelaide. Accessed August 4, 2011: http://www.caudit.edu.au/educauseaustralasia/2003/EDUCAUSE/PDF/AUTHOR/ED03101 9.PDF

Feinstein, J. (2010). Using IT when teaching mathematics classes. Presentation given November 19, 2010 at the Higher Education Academy: Maths, Stats and OR Network, Nottingham University, Nottingham, UK.

Figlio, D. N., Rush, M., \& Yin, L. (2010). Is it live or is it internet? Experimental estimates of the effects of online instruction on student learning. National Bureau of Economic Research Working Paper No. 16089, Cambridge, MA.

Goodyear, P. (2002). Teaching online. In N. Hativa \& P. Goodyear (Eds), Teacher thinking, beliefs and knowledge in higher education,79-101. Dordrecht: Kluwer Academic Publishers.

Greenberg, W. \& Williams, M. (2008). New pedagogical models for instruction in mathematics. In D. Konaté (Ed.) Mathematical Modeling, Simulation, Visualisation and e-Learning, 361371. Springer Berlin Heidelberg.

Hart, S. G., \& Staveland, L. E. (1988). Development of a multi-dimensional workload rating scale: Results of empirical and theoretical research. In P. A. Hancock \& N. Meshkati (Eds.), Human mental workload. 139-183. Amsterdam: Elsevier. 
Harzing, A. W. K., \& Van der Wai, R. (2008). Google scholar as a new source for citation analysis. Ethics in Science and Environmental Politics, 8(1), 61-73.

Hembrooke, H., \& Gay, G. (2003). The laptop and the lecture: The effects of multitasking in learning environments. Journal of Computing in Higher Education, 15(1), 46-64.

Hofacker, E., \& Ernie, K. (2009). Using digital ink and podcasts to teach mathematics. Proceedings of the International Conference on Technology in Collegiate Mathematics. Retrieved January $14^{\text {th }}, 2011$ : http://archives.math.utk.edu/ICTCM/VOL21/S010/paper.pdf.

Horrigan, J. (2009). Home broadband adoption 2009. A Report for the Pew Institute

Washington, DC, USA. Accessed August 4, 2011: http://pewinternet.com/ /media/Files/Reports/2009/Home-Broadband-Adoption-2009.pdf

Inglis, Palipana, Trenholm and Ward (in press). Individual Differences in Students' Use of Optional Learning Resources. Journal of Computer-Assisted Learning. DOI: 10.1111/j.13652729.2011.00417.x

Jadin, T., Gruber, A., \& Batinic, B. (2009). Learning with E-lectures: The meaning of learning strategies. Educational Technology \& Society, 12(3), 282-288.

Jaki, T. (2009). Recording lectures as a service in a service course. Journal of Statistics Education, 17(3). Accessed August 4, 2011: http://www.amstat.org/publications/jse/v17n3/jaki.html

Jones, S. (2007). Reflections on the lecture: outmoded medium or instrument of inspiration? Journal of Further and Higher Education, 31(4)

Joordens, S., Le, A., Grinnell, R., \& Chrysostomou, S. (2009). Eating your lectures and having them too: Is online lecture availability especially helpful in "Skills-based" courses? Electronic Journal of e-Learning, 7(3), 281-288.

Lave, J., \& Wenger, E. (1991). Situated learning: Legitimate peripheral participation. Cambridge University Press, Cambridge, UK.

Le, A., Joordens, S., Chrysostomou, S., \& Grinnell, R. (2010). Online lecture accessibility and its influence on performance in skills-based courses. Computers \& Education, 55, 313-319.

Lingefjärd, T., \& Holmquist, M. (2002). Mathematics, technology and examination in distance education. In Jarmila Novotná, J. (Ed.), Proceedings of the European Research in Mathematics Education II, 193. Accessed August 4, 2011: http://ermeweb.free.fr/doc/CERME2_proceedings

Macedo-Rouet, M., Ney, M., Charles, S., \& Lallich-Boidin, G. (2009). Students' performance and satisfaction with web vs. paper-based practice quizzes and lecture notes. Computers \& Education, 53(2), 375-384. 
Moore, D.S. (1997). New pedagogy and new content: The case of statistics. International Statistical Review, 65(2), 123-137.

Moore, M.G. (1993). Theory of transactional distance. In D. Keegan (Ed.), Theoretical principles of distance education, 22-38, NY, Routledge.

Mullamphy, P., Belward, S., Ward, L., \& Ward, P. (2009). To screencast or not to screencast. Australian and New Zealand Industrial and Applied Mathematics Journal, 51, C446-C460.

Njenga, J. K., \& Fourie, L. C. H. (2010). The myths about e-learning in higher education. British Journal of Educational Technology, 41(2), 199-212.

Overbaugh, R. C., \& Nickel, C. E. (2011). A comparison of student satisfaction and value of academic community between blended and online sections of a university-level educational foundations course. The Internet and Higher Education. 14(3), 164-174.

Owston, R., Lupshenyuk, D., \& Wideman, H. (2011). Lecture capture in large undergraduate classes: What is the impact on the teaching and learning environment? Paper presented at the Annual Meeting of the American Educational Research Association, New Orleans, US. Accessed August 4, 2011: http://www.yorku.ca/rowston/AERA2011final.pdf

Ozcinar, Z. (2009). The topic of instructional design in research journals: A citation analysis for the years 1980-2008. Australasian Journal of Educational Technology, 25(4), 559-580.

Pomper, M. (2007). Building community in an online upper-division mathematics course. International Journal of Instructional Technology and Distance Learning, 4(12), 45-61. Accessed August 4, 2011: http://www.itdl.org/Journal/Dec_07/article04.htm

Preston, G., Phillips, R., Gosper, M., McNeill, M., Woo, K., \& Green, D. (2010). Web-based lecture technologies: Highlighting the changing nature of teaching and learning. Australasian Journal of Educational Technology, 26(6), 717-728.

Pring, R. (2001). Education as a moral practice. Journal of Moral Education, 30(2), 101-112.

Pritchard, D. (2010). Where learning starts? A framework for thinking about lectures in university mathematics. International Journal of Mathematical Education in Science and Technology, 41(5), 609-623.

Redden, E. (2009). ‘An academic revolution' inside higher education: A report from UNESCO’s 2009 world conference on higher education. Inside Higher Ed. July 7, 2009. Accessed August 4, 2011: http://www.insidehighered.com/news/2009/07/07/unesco

Rood, M. (2003). Witness as participation: The lecture theatre as site for mathematical awe and wonder. For the Learning of Mathematics, 23(1), 15-21.

Smith, G. G., Torres-Ayala, A. T., \& Heindel, A. J. (2008). Disciplinary differences in E-learning instructional design. Journal of Distance Education, 22(3), 63-88. 
Tait, H., Entwistle, N.J. and McCune, V. (1998). ASSIST: a re-conceptualisation of the Approaches to Studying Inventory. In Rust, C. (Ed.), Improving students as learners (Oxford: Oxford Brookes University, Centre for Staff and Learning Development). 262-271.

Tall, D., \& Dubinsky, E. (1996). Advanced mathematical thinking and the computer. Proceedings of the 20th University Mathematics Teaching Conference, Shell Centre, Nottingham, 1-8. Accessed August 4, 2011: http://www.warwick.ac.uk/staff/David.Tall/pdfs/dot1996a-amtcomputer-umtc.pdf

Torgerson, C. J. (2006). Publication Bias: The Achilles Heel of Systematic Reviews? British Journal of Educational Studies, 54(1), 89-102.

Tsvigu, C., Breiteig, T., Persens, J., \& Ndalichako, J. (2008). Chapter 7. Promoting the learning of mathematics: On the use of learning styles in a distance education calculus course. In Holtman, L., Julie, C., Mikalsen, Ø, Mtetwa, D., Ogunniyi, M. (Ed.) Some Developments in Research in Science and Mathematics in Sub-Saharan Africa: Access, Relevance, Learning, Curriculum Research, 133-156.

Waits, B. K. (1970). Relative effectiveness of two different television techniques and one large lecture technique for teaching large enrollment college mathematics courses. Educational Studies in Mathematics, 2(4), 476-477.

Warren, E. N. (1988). The association between class size, achievement, and opinions of university students in first-semester calculus. PhD Dissertation: The University of North Texas.

Wenger, E. (2000). Communities of practice and social learning systems. Organization, 7(2), 225246.

Young, J. R. (2010). More professors could share lectures online: But should they? Education Digest, 75(9), 16-19. 


\section{Table 1:}

\begin{tabular}{lllll}
\hline Article Type & Journal & Proceedings & Other & Total \\
\hline Reflection on Traditional Practice & 9 & 0 & 3 & 12 \\
Reflection on e-Lecture Practice & 2 & 3 & 2 & 7 \\
Empirical study & 11 & 11 & 1 & 23 \\
\hline Total & 22 & 14 & 6 & 42 \\
\hline
\end{tabular}

Table 1: Articles classified by type ('other' refers to, for example, an association newsletter or book chapter). 


\section{Table 2:}

\begin{tabular}{lllll}
\hline By Method Type & Journal & Proceedings & Other & \\
\hline Self-Report & 10 & 9 & 1 & \\
Academic Records & 4 & 3 & 0 & \\
Log File Analysis & 3 & 2 & 0 & \\
Psychometric Measure & 2 & 1 & 0 & 23 Total \\
\hline Total Number & 11 & 11 & 1 & \\
\hline
\end{tabular}

Table 2: Empirical research found in journals, conference proceedings and other sources by method employed 


\section{Figure List:}

Figure 1: General research interest by article type

Figure 2: Journal research interest using pre-1993 inception journals only (conference proceedings and 'other' articles excluded) 


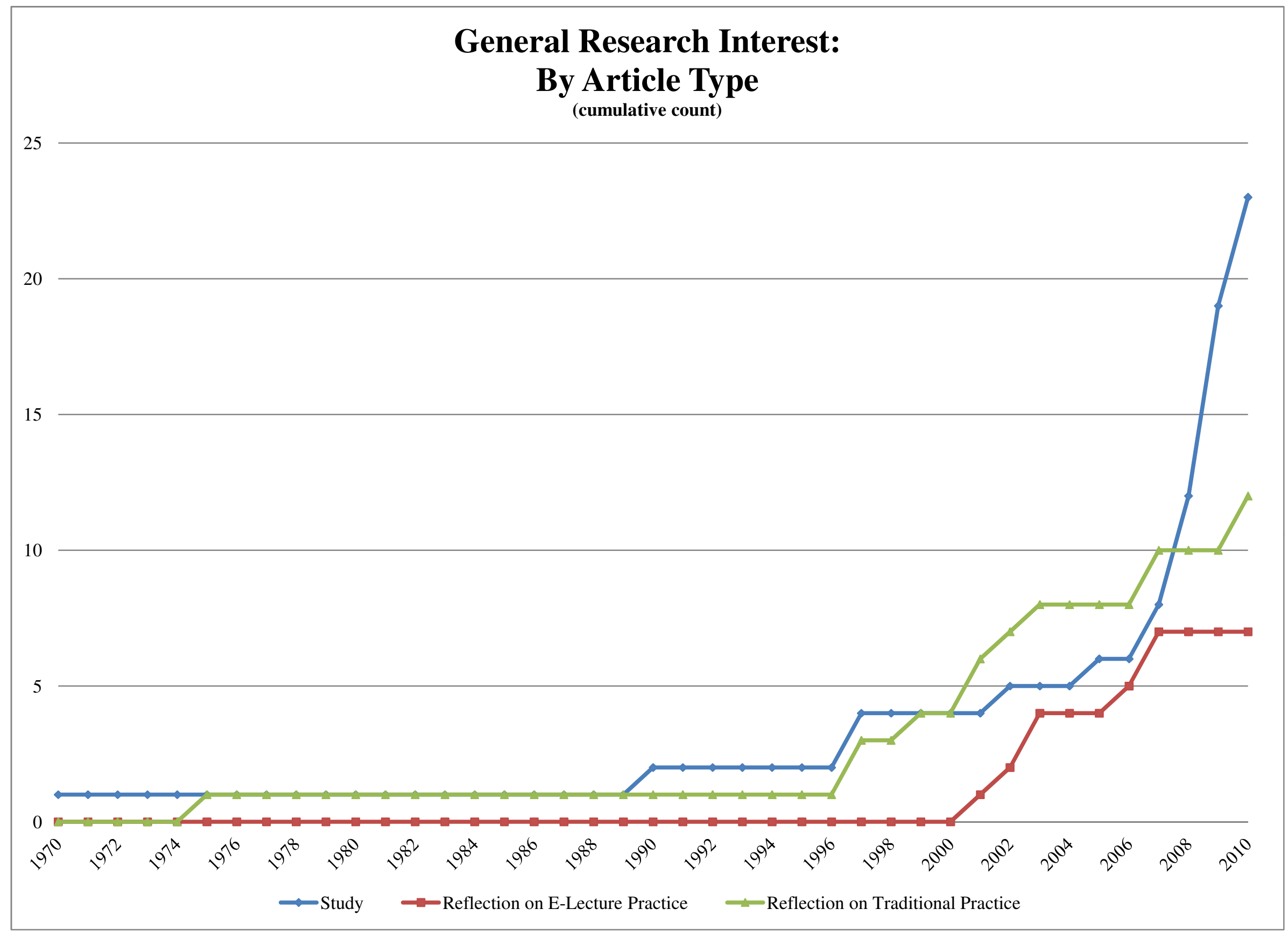




\section{Journal Article Research Interest}

(pre-1993 inception journal articles only)

25

20

15

10

5

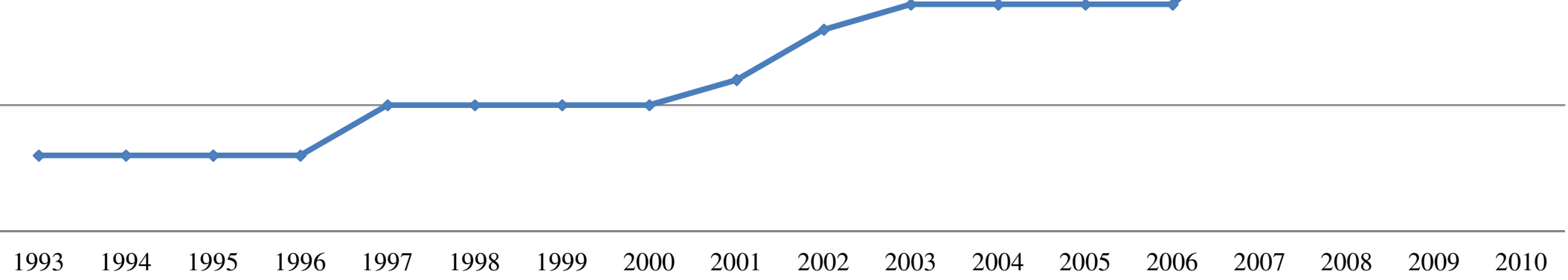

$\rightarrow$ Cumulative Count 